\title{
Electronic Information and Technology: Impact and Potential for Academic Libraries
}

\author{
Dilys E. Morris
}

This article discusses the impact of technology and the economics of information on academic libraries. It calls on libraries to forge a renewed national commitment to cooperate in the building of a national information network for scholarly communications that is based on the existing bibliographic utilities and the developing academic networks.

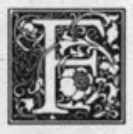

or centuries the power of information has been understood, and great efforts have gone into controlling it. But with the spread of education and literacy in the Western world during the nineteenth and twentieth centuries, the control of information and ideas has become more difficult. While experts disagree on the date, sometime during the last half-century computers and telecommunications began to converge to produce an information society which, according to Harlan Cleveland, is transforming not only our personal lives but also our national politics and our international relations. Computers have enormously increased humanity's power to think and analyze, and the telecommunications revolution allows the new knowledge being produced to spread at nearly the speed of light to anywhere in the world. As the amount of information has grown, more and more people have come to work with it-to produce, organize, distribute, use, study, control, and sell it-and whole new industries have grown up around it. In most areas decision making has become consider- ably more participatory because the volume of information available on almost any subject can no longer be digested and understood by the limited number of individuals who once made decisions.

While more information is available to greater numbers of consumers, and the spread of microcomputers in homes, offices, and laboratories makes access more widespread, there are forces working to limit access to information in electronic formats. Governments have traditionally classified information critical to national defense, but recently, however, the Reagan administration attempted to control access to unclassified but "sensitive" government information in both government and private databases through executive branch directives.

As a consequence of strong criticism aired during congressional hearings by witnesses both inside and outside of government-including librarians-one directive has been rescinded, and it appears that the other will be stopped through legislation. ${ }^{1}$ At the same time, industries attempt to control information in order to secure their competitive positions

Dilys E. Morris is Assistant Director, Technical Services, Iowa State University, Ames, Iowa 50011-2140. 
and to make money. Libraries, in a very limited fashion, are trying to make electronic information available to their users, but most charge fees to do so. Michael Nelson documents "a disturbing upward trend in the prices imposed by database producers and vendors. In the face of declining hardware and storage costs, prices for printing, displaying, or downloading online records are gradually reaching levels that inhibit their effective use as comprehensive information sources. ${ }^{\prime 2}$ These are all serious issues for librarians, but greater public attention is needed if we hope to help influence the availability of information in our society.

\section{ECONOMICS OF INFORMATION}

According to Peter Drucker, information is now our crucial resource, but its inherent characteristics are different from those of natural and manmade physical resources. Harlan Cleveland defines the differences as follows:

1. Information is expandable ... information expands as it is used. Whole industries have grown up to exploit this characteristic of information: scientific research, technology transfer, computer software . . . , and agencies for publishing, advertising, public relations, and government propaganda to spread the word (and thus enhance the word's value).

2. Information is not resource-hungry. Compared to the steel-and-automobile economy, the production and distribution of information are remarkably sparing in their requirements for energy and other physical and biological resources. Investments, pricing policies, and power relationships that assume the more developed countries will gobble up disproportionate shares of real resources are overdue for wholesale revision.

3. Information is substitutable. Information can, and increasingly does, replace capital, labor, and physical materials. Robotics and automation in factories and offices are displacing workers and thus requiring a transformation of the labor force. Any machine that can be accessed by computerized telecommunications doesn't have to be in your own inventory. ... .

4. Information is transportable. Words and numbers can be transmitted at close to the speed of light. As a result, remoteness is now more a matter of choice than geography. You can sit in Auckland, New Zealand, and play the New York stock markets in real time-if you don't mind keeping slightly peculiar hours. And the same is true, without the big gap in time zones, of people in any rural hamlet in the United States. In the world of informationrichness, you will be able to be remote if you want to, but you'll have to work at it.

5. Information is diffusive. Information tends to leak-and the more it leaks the more we have. It is not the inherent tendency of natural resources to leak. Jewels may be stolen; a lump or two of coal may fall off the railroad car on its way from Montana; there is an occasional spillage of oil in the ocean. The leakage of information, however, is wholesale, pervasive, and continuous. In the era of the institutional leak, monopolizing information is very nearly a contradiction in terms; that can be done only in more and more specialized fields, for shorter and shorter periods of time.

6. Information is shareable. Shortly before his death, the great British communications theorist Colin Cherry wrote that information by nature cannot give rise to exchange transactions, only to sharing transactions. Things are exchanged: if I give you a flower or sell you my automobile, you have it and I don't. But if I sell you an idea or give you a fact, we both have it. ${ }^{3}$

Because information may be our crucial resource and because its characteristics are different, Cleveland maintains that the way our society has traditionally controlled resources will not work for information. We will find that the institutions and systems developed for a civilization based on industrial production are inadequate for the information society. He believes that the information age is creating a new opportunity for a better society as discrimination and unfairness crumble "because the old means of control are of dwindling efficacy, secrets are harder and harder to keep, and ownership, early arrival [to valuable resources], and geography are of dwindling significance in getting access to the knowledge and wisdom which are the really valuable legal tender of our time. ${ }^{\prime \prime 4}$ Yet viewed from a different perspective, the democratization of information, in which libraries have played an important role, is at risk. Both the private and governmental sectors, for new and differing reasons, impede the free flow of information. In this pivotal environment, where access to information could improve or denigrate, the civic role of librarians grows increasingly important, and we 
must continue to strengthen and uphold it. The changes caused by the "informatization" of society will greatly impact libraries, and we should take an active role in shaping the future.

\section{IMPACT OF TECHNOLOGY}

The adoption of technology by society is generally divided into three stages. In the first, we continue to do familiar and traditional things we have always done, but we do them better and faster. In other words, we mechanize. During the second stage, the tasks themselves change because technology has revised what we do, and things are done that were never done before. Finally, in the last stage, technology causes our society itself to change, and fundamental changes in life-styles and institutions occur. This transformation is clearly illustrated by the invention of the internal combustion engine and the enormous changes the development of the automobile caused in our society.

While there is a subtle continuum in the adoption of technology, most libraries are experiencing the first phase of technological change as they automate circulation, acquisitions, card catalog production, and serials control. We have not changed what we do for the most part; instead we have simply improved the way we do it through mechanization. Now that we are entering the second phase, we begin to think about what we do rather than just how we do it. The online catalog with its enhanced keyword and Boolean access allows retrieval never before possible. Database search services are moving reference librarians into stage two as they perform tasks very different from traditional duties. As we progress through this phase, there will be many more significant changes in the services libraries offer, how libraries are organized to provide these services, and how they interrelate with other institutions.

Rowland C. W. Brown, president and CEO of OCLC, predicts that the opportunity to improve and change services radically will become more viable because the technological advances being made now are in areas important to library development. Developing technology is divided into three categories or abilities: (1) to process and compute data, (2) to store data, and (3) to retrieve, communicate, and reproduce data. Until fairly recently most of the advances were in the first category, processing power. For libraries to make real changes, improvements in storage and communication technologies are needed. These advances are occurring now but unfortunately, software still lags significantly behind hardware, and the full potential for improvement is many years away. Because new technologies often go beyond our range of experiences, we tend to overestimate what will happen in the next five years and underestimate longer-range possibilities. We are also constrained by institutional barriers and inadequate financial resources.

\section{"The use of BITNET and the pro- posed expansion of NSFnet for schol- arly communication illustrate how scholars are changing their work, study, and research habits."}

\section{CHANGING SCHOLARLY COMMUNICATIONS}

Most libraries are marginally involved in the use of electronic information through online database searching and the newer CD-ROM databases. While the sale of commercially available information in electronic format is growing rapidly, libraries represent only a small percentage of these sales. At the same time, networks for the exchange and distribution of noncommercially available information are increasing in the private and public sectors. The National Science Foundation's new networking program, NSFnet, was planned for high-speed access to supercomputers.

In the second phase it will be expanded to a communications network for the nation's research scientists and engineers. ${ }^{6}$ BITNET, the interuniversity communications network, is open to any college or university for scholarly and administrative communications, and is also used to exchange manuscripts with publishers 
and scholarly materials between colleagues. Funding has been secured from NSF for a prototype experiment to connect BITNET with NSFnet. This connection would give BITNET members full access to the computers in the planned NSFnet.

The use of BITNET and the proposed expansion of NSFnet for scholarly communication illustrate how scholars are changing their work, study, and research habits as they become more computer-literate and as more personal computers become available for use. It appears that unless libraries increase their use of telecommunications technology and services, scholars will seek other agencies to meet their needs. Testifying before a congressional hearing on access to electronic databases, Robert L. Parks, director of the Office of Public Affairs of the American Physical Society, said,

We are fast approaching the day when electronic databases will largely supplant conventional libraries as the repository of scientific and technical information and will become the preferred means by which scientists communicate their findings.

In a recent article, Clifford Lynch and Edwin Brownrigg, former director of the Division of Library Automation at the University of California, Berkeley, predicted that

if libraries are to survive as viable services, they must not only understand current computing and telecommunications technologies, but they must develop and execute effective plans to implement these technologies. .... We would suggest that the place to start is with the development of effective library computer and telecommunications networks and their integration [into] existing national networks. ${ }^{9}$

\section{EXPANDING ELECTRONIC INFORMATION}

Although publishing economics is driven by print products, the growing use of electronic information may eventually shift the balance. The economic reliance on printed indexes to subsidize electronic delivery is changing for Chemical Abstracts. According to Harry Boyle,

We are now in the mode where printed product revenue is declining despite price increases on the printed product. The revenue base for the printed product is shrinking. The revenue base for the electronic product is growing. Fifteen years ago the printed product was paying the bills. In the next five years, the electronic form of the product will be the dominant way that the database is used and the printed will become secondary. We are rapidly approaching the point where the electronic use of the product is in fact generating a lot of the revenue needed to build the database, and the printed product is becoming the secondary concern. I don't think we will stop the printed product. But if you look at the economics inside the company, you'll know that electronic use is paying the bills and it is subsidizing the printed product which is an exact reverse of what we saw 15 years ago. So, we're in a transition mode. ${ }^{10}$

The Europe-based ADONIS project, designed to give access to biomedical journal articles and the associated indexing through CD-ROM technology, is functioning in a test mode. Developers are exploring the feasibility of publishers supplying their journals in machine-readable form to document delivery centers that print articles on demand. The objectives of the project, a study of the impact of this service on library users, are to provide insight into information repackaging, implementation of digital technology, and the economics of electronic publishing. ${ }^{11}$

OCLC has expanded into Europe and the Far East. It is working towards delivery of information to users, not just bibliographic citations to librarians. To this end, OCLC is designing a full subject/reference search system for the OCLC database, planning to use this searching software to access separate research databases through an intelligent gateway. With the improvement in facsimile devices and telecommunications, OCLC sees the possibility of not only searching and locating data but also transmitting text to the user.

OCLC is currently experimenting with EIDOS, which provides for browsing and electronic delivery of selected portions of monographic texts. Research has shown that readers only consult certain types of nonfiction books for specific information. Although they check indexes and review the table of contents, they do not read the entire monograph. OCLC might store the text of such monographs in its central 
database and load the indexes and tables of content in a library's online catalog. Users would search indexes online and then request appropriate portions of the text from OCLC by telecommunications. ${ }^{12}$ Graph-Text is an OCLC electronic journal development project developed with the American Chemical Society and Chemical Abstracts. It stores the full text and graphics of articles on CD-ROM, using a powerful search engine that allows full-text searching and reviewing of searches and a laser printer to print the results. ${ }^{13}$

The distribution of government documents in electronic format (Depository Library System) is still uncertain, but OCLC may play a role in transmitting this information to libraries. Current discussions point toward a layered network in which OCLC, other nonprofit networks, and resource libraries with the computer capability to handle a variety of electronic formats would become the conduits for government publications.

BRS/Onsite, which makes databases available locally for a fixed price, includes national bibliographic databases loaded in the BRS format, search and retrieval software, a gateway to the BRS online service, and support. Experimentation has begun in loading these national bibliographic databases on local computers and extending access universitywide. Georgia Institute of Technology implemented its Library 2000 system in November 1986 . It provides access to books, documents, and four periodical databases. Students and faculty have remote, free access to any of the databases mounted on the university's mainframe computers. ${ }^{14}$

\section{INFORMATION DELIVERY AND NEW LIBRARY ROLES}

Most libraries focus on access to material that they own. Surely this focus must change as more current information becomes available in electronic databases that are used but not owned. We will need to think more about providing information to users rather than directing them to packages of information (books, journals, etc.).

As technology multiplies the available information, there will be a greater need for access, interpretation, and brokering.
Librarians are well situated to perform this role, but it will require considerably increased information skills and more staffing. In a recent editorial in Change, Frank Newman, president of the Education Commission of the States, discussed the traditional purpose of the academic library-to acquire and loan material to scholars. He concluded that this approach will no longer serve us well because of the developments in telecommunications and computer applications: "Perhaps we have already reached the point where the central purpose of the library, rather than acquisition of materials for loan to scholars, will be the connection of the scholar to different forms of information located in widely diverse places. The major time of the library staff and the resources of the library system will then be deployed in the making of these connections."

In the same issue, Patricia Senn Breivik covered the "Libraries and the Search for Academic Excellence" symposium held at Columbia University in March 1987. The major theme was the changing role of academic libraries in the information age. The overall picture emerging from this symposium is that libraries must become more active partners in the educational arena and that libraries must be involved in preparing students to educate themselves throughout their lives. According to University of Colorado President E. Gordon Gee, a driving force behind the symposium, "We must not only train students to seek the knowledge and wisdom of past generations, but prepare them to use libraries as vital, dynamic resources." ${ }^{16}$

"Can the developing technologies be used to reduce the local cataloging and maintenance efforts further, in order to shift staffing into information provision and instruction?"'

\section{BIBLIOGRAPHIC CONTROL AND CHANGING PERSPECTIVES ON LIBRARY CATALOGS}

In the area of bibliographic control and access, libraries have worked for nearly a century to establish rules and standards 
governing the description and organization of fixed-format materials displayed in card catalogs or early versions of online catalogs. How will we, or indeed, will we catalog and provide access to electronic information that can be combined and recombined on an ad hoc basis? Will there be an archival need for electronic information for historical purposes? Will book cataloging continue to be a local library process, or will it become part of the publishing process? Can the developing technologies be used to reduce the local cataloging and maintenance efforts further, in order to shift staffing into information provision and instruction?

User expectations increase with the advent of online catalogs. Once electronic access is available for book and journal titles, requests grow for similar access to journal articles. Remote access accelerates computer and terminal usage within the academic community and stimulates networking. There is a new interest in expanding the scope of online catalogs to include all types of divergent collections held across campus but not owned by the library, such as machine-readable data-files and software collections, and collections held outside the university, such as the collections at the Center for Research Libraries. Will managers of local online catalogs be able to adjust quickly enough to accommodate requests to enlarge the scope of library catalogs? While automated authority control improves, its development is not keeping up with the changing perspectives of the online catalog. At the same time, online catalogs and acquisitions and serials control systems are reducing the need for centralization of technical services activities because the control records can be made available remotely wherever a terminal can be connected. Such connections become easier with the development of local area networks.

With the advent of online catalogs and acquisitions and serials control systems, libraries are discovering that their traditional organizations may no longer be effective and that new approaches are needed. If technology affects our work and services as this discussion suggests, then our organizations will become even more archaic, and significant rethinking will be required for internal and external relationships with other units, agencies, or institutions and for providing new and needed services.

\section{FUNDING ISSUES}

Libraries are not usually generously funded, and many are now facing severe budget problems as the prices for books and journals, particularly those from abroad, continue to spiral. How can libraries stretch already thin acquisitions budgets to cover the expanding electronic information? How will libraries finance the required hardware and software, particularly when obsolescence is rapid and most budgets are annual without mechanisms to save for future capital outlays? How will libraries finance staff training and development in a rapidly changing technological environment? What can libraries do to alert funding agencies to the problems of cost and public access to electronic information in this new era? Will we continue to charge user fees to access electronic information as it becomes a more prevalent information tool, or can new funding approaches be found? Will the spread of electronic information cause significant changes in the publishing industry, particularly in the areas of academic research and scholarship?

\section{NEW DIRECTIONS FOR SCHOLARLY PUBLISHING}

Douglas E. Van Houweling, vicepresident for Information Technology at the University of Michigan and a member of the OCLC Research Advisory Council, suggests that, working together, libraries, computing centers, and university presses could provide new directions for scholarly publications and, thereby, reduce delays in costs. He points out that many of the elements to change scholarly publishing are now in place, but cooperation and organization are needed to reuse the available tools. Increasing numbers of faculty members are drafting their publications on microcomputers, and standards for producing and transmitting them between editors and review boards are under development. University networks are facilitating the transmission of papers within the university, and a large 
number of institutions of higher education are being networked together, as noted earlier, so information can be moved between institutions.

Van Houweling's scenario is intriguing. A scholar with a draft paper creates a preliminary catalog record for the local online catalog by interacting with an expert system. The paper is read electronically by peers. When ready, the paper is transmitted electronically to the journal editor and review board. After all revisions are made, the article is accepted and added to the table of contents. The library is notified electronically, and the cataloging record is updated as appropriate by both publisher and library. The paper gains full publication status. Van Houweling sees the same pattern for book publication and suggests that if libraries install facilities for demand printing of electronic publications, they "would not only avoid many of the costs involved in subscribing to a printed journal or buying a book, but would also become a more integral part of the active scholarly life of the university by capturing publications for broad access at an early stage in their creation.",17

\section{GOVERNMENT INFORMATION IN ELECTRONIC FORMAT}

There is some question as to whether government information in electronic format will be as readily available as its printed precedents. While the legislation enacting the Depository Library System was written before electronic information was envisioned, it is not precluded. The position of many librarians is that equitable citizen access to government information in electronic formats is as essential to the public good as is access to other forms of government information. Equitable access through library information systems is threatened, however, by government policies that seek to restrict the availability of this information and by the fears of the private sector that availability through the Depository Library System (without proper safeguards) encroaches upon its ability to compete in the open market.

\section{NEED FOR CHANGE}

It is imperative that librarians focus on the issues raised here and explain them to li- brary users and funding agencies. If the experts are correct about the impact of information and technology on our society, we must be prepared either to change or accept a steadily diminishing role. This does not mean that printed books, serials, and other traditional library materials will not be important tools for our society. It does mean that electronic information will become as important. If librarians do not incorporate electronic access to information, a substantial number of current users will obtain their information from other sources. It also means that the expanding information age will require new roles for librarians and that we must begin to anticipate these and to plan for our changing future.

\section{OPPORTUNITIES AND THREATS}

The information revolution is here. It will continue to change our society profoundly. The use of information technology can enhance or diminish the quality of our lives because people can be enfranchised or disenfranchised depending upon their ability to gain access to information. We are in a transition period, wavering between increased opportunities resulting from the information age and the threat of a more controlled society with less access to information and reduced freedoms. Libraries and their networks have a responsibility to ensure access to information. This can best be achieved by joining together in the development of a national information network.

\section{A NATIONAL LIBRARY INFORMATION NETWORK}

Electronic information will expand, supplement, and replace certain printed information collected by academic libraries. Scientists and scholars in growing numbers are using electronic networks to use and share information. BITNET is currently being used by approximately 350 member institutions to communicate scholarly and administrative data. OCLC alone connects over 6,000 libraries, of which more than 1,200 are academic and research libraries and another 300 in junior and community colleges. As scientists, engineers, and some humanists and social scientists attempt to create a national network for re- 
search communications through networks like NSFnet and BITNET, we need to look at the enormous networks that connect libraries to see if a new and wider approach to academic communication can be achieved. OCLC is currently engaged in discussions with EDUCOM about its plans for the management, operation, and information services of BITNET in an effort to coordinate and impact on a future academic network. Librarians should encourage and financially support efforts to create a national information network.

In addition to the computerized networks that connect libraries around the globe, librarians bring highly developed skills to organizing, indexing, and accessing information. Library schools and bibliographic networks are engaged in substantial research to improve these skills for the new information age. National and international standards have been created to describe and index information. If we could combine our skills and commitment, bibliographic utilities, and other national and local information systems to create a national information network, electronic information could be shared between libraries, scholars, and scientists. Libraries will need to reutilize and strengthen staffs to provide sophisticated electronic information access and instruction. A national effort to build a scholarly communications network will need to provide support to do this. This response to electronic information could transform scholarly communications, put libraries and librarians in the forefront of accessing electronic information, and move libraries firmly into the second stage of the adoption of technology described earlier.

\section{A NEW COMMITMENT TO LIBRARY COOPERATION}

To build a national information network would require a renewed commitment to library cooperation as well as financial support from libraries and their parent institutions. Academic and research libraries would need a joint national campaign to explain the challenges and opportunities of electronic information and networking to their parent institutions, computing centers, and funding agencies, and they would need to support the bibliographic utilities in their effort to create a national network for scholarly communications.

In order to foster and develop a scholarly communications network and new, unique information services, academic and research librarians must investigate a number of possible cooperative activities. A database of current unpublished and ongoing research accessible through the bibliographic utilities would provide a powerful new tool for scholarship. If we were able to build a national database of cataloging records for published material, surely a similar database of current scholarly research could also be built in conjunction with scholars and expert systems. We could also investigate whether a change in the scholarly publishing process could follow from a national current research database.

Future enhancements to library services will require much more research on the use, access, and impact of electronic information and the role of expert systems. The Council on Library Resources joint grant to the University of Michigan School of Information and Library Studiēs and OCLC to study the means of increasing accessibility to Library of Congress Subject Headings in online bibliographic systems is an example of how libraries can not only improve access but also find new ways of using technology to reduce local cataloging and maintenance activities. Libraries should encourage this type of research.

It is now time to begin strategic planning for a significantly different future. Joined together in large membership organizations, such as OCLC with established research facilities and technological knowledge, librarians have an opportunity to become change agents in society and to play a role in reshaping the communications of scholarship and contributing to the free flow of information. If we do not take an active role in shaping access to electronic information, then it is highly likely that the growth of electronic information and telecommunications networks for information transfer will diminish the role of the library and librarians in the dissemination of information. The effect on the democratization of information could well be negative. 


\section{REFERENCES}

1. Association of Research Libraries, Newsletter 134:9-11 (Mar. 26, 1987) and 136:9 (Aug. 17, 1987).

2. Michael L. Nelson, "High Database Prices and Their Impact on Information Access: Is There a Solution?" The Journal of Academic Librarianship 13:159 (July 1987).

3. Harlan Cleveland, "Education for the Information Society," Change 17:15-16 (July/Aug. 1985).

4. Ibid., p.16.

5. Rowland C. W. Brown, Background paper for remarks to users council meeting on new technology directions, Feb. 8, 1987.

6. Dennis M. Jennings and others, "Computer Networking for Scientists," Science 231:943-50 (Feb. 28, 1986).

7. Daniel J. Oberst and Sheldon B. Smith, "BITNET: Past, Present, and Future," EDUCOM Bulletin 21:10-17 (Summer, 1986).

8. Judith Axler Turner, "Effort to Limit Access to Unclassified Data Bases Draws Criticism," Chronicle of Higher Education 33:12 (Mar. 4, 1987).

9. Clifford A. Lynch and Edwin B. Brownrigg, "The Telecommunications Landscape: 1986," Library Journal 111:46 (Oct. 1, 1986).

10. Jeffery K. Pemberton, "Online Interviews Harry Boyle on CAS's New License Policy . . Effects on Searching/Prices," Online 12:21 (Mar. 1988).

11. "Report on the 53rd Council and General Conference of the International Federation of Library Associations and Institutes, Brighton, United Kingdom," Library of Congress Information Bulletin 47:147-49 (Apr. 11, 1988).

12. OCLC Online Computer Library Center, Inc., Office of Research and Technical Planning, Annual Review of OCLC Research, July 1985-June 1986 (Dublin: OCLC, c1986), p.15, 17-18.

13. Ibid., p.16.

14. Miriam A. Drake, "Library 2000-Georgia Tech: A Glimpse of Information Delivery Now and in the Year 2000," Online 11:45-48 (Nov. 1987).

15. "Adapting Academic Libraries to the Future," Change 19:4-5 (July/Aug. 1987).

16. Patricia Senn Breivik, "Making the Most of Libraries," Change 19:44-52 (July/Aug. 1987).

17. Douglas E. Van Houweling. "The Information Technology Environment of Higher Education," Campus of the Future; Conference on Information Resources (Dublin: OCLC, c1987), p.61-106.

The library's function is to promote the effective use of graphic materials. If a student does not understand the meaning of such symbols, if he cannot read rapidly and understandingly, he cannot profit fully from the special means of education for which the library has been established and is maintained to provide.

-Louis R. Wilson, "The Library's Role in College Instruction" (March 1944), p.133 